\title{
Is There a Duty to Be a Digital Minimalist?
}

\author{
Timothy Aylsworth and Clinton Castro
}

\section{Florida International University, Department of Philosophy}

Pre-production copy. Please cite to final version:

https://onlinelibrary.wiley.com/doi/abs/10.1111/japp.12498?af=R

\begin{abstract}
The harms associated with wireless mobile devices (e.g., smartphones) are well documented. They have been linked to anxiety, depression, diminished attention span, sleep disturbance, and decreased relationship satisfaction. ${ }^{1}$ Perhaps what is most worrying from a moral perspective, however, is the effect these devices can have on our autonomy. In this paper, we argue that there is an obligation to foster and safeguard autonomy in ourselves, and we suggest that wireless mobile devices pose a serious threat to our capacity to fulfill this obligation. We defend the existence of an imperfect duty to be a "digital minimalist." That is, we have a moral obligation to be intentional about how and to what extent we use these devices. The empirical findings already justify prudential reasons in favor of digital minimalism, but the moral duty is distinct from and independent of prudential considerations.
\end{abstract}

"[People] have become the tools of their tools." Henry David Thoreau, Walden, ch 1.

Keywords: applied ethics; ethics of technology; Kantian ethics; autonomy; duties to oneself

\section{Introduction}

"I wish I could read. I really do," says comedian Esther Povitsky. "I try to read. I buy books. I open books. And then I black out and I'm on Instagram, and I don't know what

\footnotetext{
${ }^{1}$ It would be difficult to provide an exhaustive list. The empirical literature on this issue is vast; we catalog many of the harms in section 2. For a review of the literature in psychology, see José De-Sola Gutiérrez, Fernando Rodríguez de Fonseca, and Gabriel Rubio, 'Cell-Phone Addiction: A Review', Frontiers in Psychiatry 7 (2016); Yu-Kang Lee, Chun-Tuan Chang, You Lin, and Zhao-Hong Cheng, 'The Dark Side of Smartphone Usage: Psychological Traits, Compulsive Behavior and Technostress', Computers in Human Behavior 31 (2014): 373-83; Tingting Gao, Yu-Tao Xiang, Han Zhang, Zhao Zhang, and Songli Mei, 'Neuroticism and Quality of Life: Multiple Mediating Effects of Smartphone Addiction and Depression', Psychiatry Research 258 (2017): 457-61; Valentina Rotondi, Luca Stanca, and Miriam Tomasuolo, 'Connecting Alone: Smartphone Use, Quality of Social Interactions and Well-Being', Journal of Economic Psychology 63 (2017): 17-26; L.D. Rosen, K. Whaling, S. Rab, L.M. Carrier, and N.A. Cheever, 'Is Facebook Creating 'IDisorders'? The Link between Clinical Symptoms of Psychiatric Disorders and Technology Use, Attitudes and Anxiety', Computers in Human Behavior, 29, 3, (2013): 1243-54; Sara Thomée, Annika Härenstam, and Mats Hagberg, 'Mobile Phone Use and Stress, Sleep Disturbances, and Symptoms of Depression among Young Adults - a Prospective Cohort Study', BMC Public Health, 11, 1 (2011): 66;Éilish Duke and Christian Montag, 'Smartphone Addiction, Daily Interruptions and Self-Reported Productivity', Addictive Behaviors Reports 6 (2017): 90-95.
} 
happened." To many of us, this is a familiar occurrence. All too often we set out to complete a task but are interrupted and subsequently derailed by our wireless mobile devices.

At a glance, it appears that we are falling short only in a prudential sense when we succumb to these distractions; we are failing to do what is in our own self-interest (e.g., read more). But incidents of this kind might also involve a moral failure. For insofar as we are morally required to cultivate and protect our autonomy, we fail to meet this requirement by falling prey to mobile phone addiction. In this paper, we explain and defend this requirement, grounding it in a Kantian account of duties to oneself.

The structure of the paper is as follows. In the next section, we introduce digital minimalism, the idea that our interactions with digital technology should not conflict with our autonomously adopted ends. ${ }^{2}$ In section 3, we argue for the existence of self-regarding duties. In section 4 , we complete the argument by connecting our discussion of self-regarding duties to digital minimalism. We argue that there is an imperfect duty to be intentional about our use of wireless mobile devices and other addictive technologies, that is, to be digital minimalists. Although our account is broadly Kantian, we are not committed to Kant's views about particular duties to oneself (e.g., the prohibition of suicide, the obligation to cultivate talents, etc.). For our purposes, what is important about his view is the absolute value of rational agency, the humanity formulation of the categorical imperative, and the distinction between perfect and imperfect duties.

\section{Digital Minimalism}

A great deal has been written about the harmful effects of the addictive behaviors associated with wireless mobile devices. These addictive behaviors are well known. For many people, their smartphone is the first thing they see in the morning and the last thing they see at night. ${ }^{3}$ The average user unlocks their phone nearly 100 times per day. ${ }^{4}$ Studies on students have shown that they are so addicted to their phones that being separated from it (or required to turn it off) causes anxiety. ${ }^{5}$ Students who are addicted to their phones tend to do worse academically than their peers who are not. ${ }^{6}$ Many writers in the popular "self-help" literature point out how

${ }^{2}$ This term was coined by Cal Newport, Digital Minimalism: Choosing a Focused Life in a Noisy World (New York: Portfolio, 2019); our understanding of digital minimalism is inspired by but differs from Newport's, as we explain in section 2 .

${ }^{3}$ Catherine Price, How to Break Up with Your Phone (New York :Ten Speed Press, 2018).

${ }^{4}$ Estimates vary from as low as 50 to as high as 150 , but this figure of 96 unlocks per day comes from a 2019 survey by a market research firm. Young people (ages 18 to 24) look at their phones about twice as much as older users. See Asurion, 'Americans Check Their Phones 96 Times a Day', (2019) Accessed May 25, 2020, https://www.prnewswire.com/news-releases/americans-check-their-phones-96-times-a-day-300962643.html.

${ }^{5}$ See Nancy A. Cheever, Larry D. Rosen, L. Mark Carrier, and Amber Chavez, 'Out of Sight Is Not out of Mind: The Impact of Restricting Wireless Mobile Device Use on Anxiety Levels among Low, Moderate and High Users', Computers in Human Behavior 37 (2014): 290-97; Rosen et al. op. cit.; Olatz Lopez-Fernandez, Daria J. Kuss, Lucia Romo, Yannick Morvan, Laurence Kern, Pierluigi Graziani, Amélie Rousseau, et al, 'Self-Reported Dependence on Mobile Phones in Young Adults: A European Cross-Cultural Empirical Survey', Journal of Behavioral Addictions, 6, 2 (2017): 168-77.

${ }^{6}$ Kuznekoff op. cit. 
people are often using their phones in ways that they do not want to use them. ${ }^{7}$ They are often using their phones instead of having face-to-face interactions, which diminishes the quality of their interpersonal relationships. ${ }^{8}$ They have shorter attention spans, and they struggle to stick to a task without frequent distractions from their phones. ${ }^{9}$

Further, wireless mobile devices are designed to be addictive. Consider the popular design guide Hooked: How to Build Habit-Forming Products by Nir Eyal, which leverages findings in behaviorist psychology to intentionally create "habits", which Eyal identifies as behaviors that become automatic through repetition. ${ }^{10}$ The Hooked model of forming habits involves repeatedly running users through the "Hook Cycle", which should be familiar to anyone who uses smartphone apps:

1. Trigger: bring the users attention to an app via, e.g., a notification;

2. Action: get the user to do something, e.g., visit the site to check their feed;

3. Variable reward: tie the action to a reward, but one that is sometimes highly rewarding - perhaps a notice that one's post is trending — and sometimes not, such as a notification that a friend has made a post.

4. Investment: have the user make an investment-e.g., changing their profile picture or making a post - so that they will be motivated to come back to the site.

This is an instruction set for turning a mobile device into a Skinner box. As Eyal states,

"Research shows that levels of the neurotransmitter dopamine surge when the brain is expecting reward [...] which suppresses the areas of the brain associated with judgement and reason while activating the parts associated with wanting and desire."11

${ }^{7}$ Price op. cit. and Newport op. cit. This is not just the conclusion of self-help authors; many people self-report that they use their phone more than they would like. According to a 2018 survey, $39 \%$ of respondents said that they used their phones too much. Among users aged 18 to 34, 60\% claimed that they used their phone too much. See Jamie Beningfield "Study Reveals How Often We Look At Our Phones In A Day" BrainSharper (2018) https://www.brain-sharper.com/entertainment/how-often-look-phones-day/.

${ }^{8}$ One phenomenon is so commonplace that it has given rise to the term "phubbing" (a portmanteau of "phone" and "snubbing"). Unsurprisingly, a number of studies have confirmed that phubbing loved ones is associated with decreased satisfaction in those relationships. See Rotondi op. cit. and Varoth Chotpitayasunondh and Karen M. Douglas, 'How 'Phubbing' Becomes the Norm: The Antecedents and Consequences of Snubbing via Smartphone', Computers in Human Behavior 63 (2016): 9-18.

${ }^{9}$ Jeffrey H. Kuznekoff, Stevie Munz, and Scott Titsworth, 'Mobile Phones in the Classroom: Examining the Effects of Texting, Twitter, and Message Content on Student Learning', Communication Education, 64, 3 (2015): 344-65. One study showed that those who checked apps because of notifications took four times as long to complete a task as those who did not (Luis Leiva, Matthias Böhmer, Sven Gehring, and Antonio Krüger, 'Back to the App: The Costs of Mobile Application Interruptions' in Proceedings of the 14th International Conference on Human-Computer Interaction with Mobile Devices and Services - MobileHCI '12 (San Francisco: ACM Press, 2012). Smartphone addiction has unsurprisingly been linked to decreased productivity. See Duke and Montag op. cit.

${ }^{10}$ Nir Eyal, Hooked: How to Build Habit-Forming Products (New York: Penguin Books Limited, 2014) at Introduction, fn. 6.

${ }^{11}$ Eyal op. cit. at p. 7, emphasis added. 
Eyal elaborates on this, saying that it is the secret behind "many other habit-forming products", such as "slot machines and lotteries". ${ }^{2}$

It is hardly a stretch to say that mobile devices pose a threat to our autonomy, our capacity to set and pursue our chosen ends. By forfeiting some of our agency to our phones (or other addictive devices), ${ }^{13}$ we diminish our capacity to pursue the ends that we have set for ourselves and instead serve the interests of the developers of those products, which usually involves spending as much time on our devices as possible. Povitsky's situation demonstrates what this looks like. She was unable to achieve the end she set (reading a book) due to compulsive smartphone use. There is more going on here than the mere opportunity cost of looking at the phone instead of the book. As Eyal points out, as we become addicted to the dopamine surge we get from our phones, we weaken our frontal lobe's executive function, and this makes us worse at sticking to a task like reading a book. ${ }^{14}$

In order to substantiate the claim that smartphone addiction undermines autonomy, we must say more about the concept at issue. Personal autonomy has been defined in a variety of ways, but we believe that a minimal definition of "self-governance" is sufficient for our purposes here. Many of the more specific models should yield the conclusion that many of us are not autonomous with respect to our smartphone usage. To see this, let's return to Povitsky's case. According to the Frankfurt/Dworkin model, Povitsky's first-order desire to check Instagram while reading is inconsistent with her higher-order desire, i.e., to want to want to read (or, perhaps more accurately, to want to not want to check Instagram while reading). ${ }^{15}$ On Watson's characterization, what is distinctive about compulsive behavior is that "the desires and emotions in question are more or less radically independent of the evaluational systems of these agents."16 Povitsky's smartphone use is inconsistent with her evaluative judgments about what she ought to be doing, and the behavior is compulsive. Bratman defends a model of autonomy that requires

${ }^{12}$ Eyal op. cit. at p.7.

13 Smartphones are by no means the only addictive device, nor are they the only form of technology designed to capture our attention. Television is surely meant to do the same thing. For instance, someone might become addicted to watching Netflix or YouTube on the computer. Although these are notable similarities, the seductive nature of smartphones is unique in some important ways. We explain below some of the things that are distinctive about the problematic use of these devices. Not only are they a nearly indispensable part of modern life, they are almost always on one's person, dinging with notifications that remind us to check in with them regularly. This is an important difference. As we will argue, these disruptions are especially problematic when it comes to our capacity to focus and exercise our rational agency.

${ }^{14}$ Indeed, this is precisely the claim made by Nicholas G. Carr, The Shallows: What the Internet Is Doing to Our Brains (New York: W.W. Norton, 2011); he argues that the internet has fundamentally changed how we "think, read, and remember." He specifically singles out reading books as an activity that has become more difficult because of the effect that the internet has on us.

15 See Harry Frankfurt, 'Freedom of the Will and the Concept of a Person', Journal of Philosophy, 68, 1 (1971): 5-20 and Gerald Dworkin, The Theory and Practice of Autonomy (Cambridge; New York: Cambridge University Press, 1988).

${ }^{16}$ Gary Watson, 'Free Agency', The Journal of Philosophy, 72, 8 (1975): 205-20, p 220. 
"harmony between what the agent does and her more or less long-term plans." "1718 Surely Povitsky's behavior fails on this count as well — we can suppose that Povitsky, like many of us, would like to read many books over the course of her life, and to develop a disposition to being able to sit and enjoy reading for long stretches. The action of looking at her phone compulsively is not consistent with her long-term plans.

No matter which model one adopts, the result is likely to be the same. Povitsky is not autonomous with respect to her smartphone usage. And her case is not exceptional. Many people find themselves appalled when confronted with data showing them how much they use their phones. ${ }^{19}$ They frequently voice a desire to reduce their smartphone usage. They believe that the use of their phone interferes with their pursuit of more worthwhile goals.

Here it is fair to ask whether smartphone addiction is unique or if it is like any other addiction. We think that smartphone addiction is unlike other addictions - such as addictions to cigarettes, coffee, or even running. ${ }^{20}$ Smartphone addiction fuels interruptions that acutely and repeatedly interfere with our ongoing mental and physical tasks. ${ }^{21}$ This is, in part, because smartphones are designed to capture our attention. Smartphones-as well as other internet-connected devices - are implicated in the attention economy, an economy of mostly "free" products funded by advertising that is only worthwhile to its purveyors if it can capture users' attention. Smartphone addiction poses a distinct threat to our rational capacities because an effect of the addiction is susceptibility to having one's attention hijacked at frequent intervals, interrupting one's ongoing tasks.

${ }^{17}$ Sarah Buss and Andrea Westlund, 'Personal Autonomy', In The Stanford Encyclopedia of Philosophy, edited by Edward N. Zalta, Spring 2018. Metaphysics Research Lab, Stanford University. https://plato.stanford.edu/archives/spr2018/entries/personal-autonomy/.

${ }^{18}$ Cf. Michael Bratman, 'Practical Reasoning and Weakness of the Will', Noûs, 13, 2 (1979): 153, and

Michael Bratman, Structures of Agency: Essays (Oxford: Oxford University Press, 2007).

${ }^{19}$ Newport op. cit. and Price op. cit. make this claim, and survey data support it. See note 7 above.

${ }^{20}$ If the Kantian argument about addiction and autonomy is right, it could be the case that certain substances and behaviors threaten our autonomy as well, and thus there is a Kantian obligation to resist addictions to coffee, cigarettes, etc. We will not take a stand on that matter here. For an interesting discussion of duties to the self and the smoking case, see Schofield, Paul, 'On the Existence of Duties to the Self (and Their Significance for Moral Philosophy)', Philosophy and Phenomenological Research, 90, 3 (2015): 505-28.

What is important for our argument is that even if these addictions do threaten our autonomy, we think that there is something unique about smartphone addiction that poses a distinctive threat to our autonomy. Part of our argument is that smartphone addiction typically involves direct threats to rational agency, such as diminished attention span. Cigarette and coffee addictions do not seem to have this effect. One might respond that the desires to, say, take a smoke break constitute disruptions to thinking analogous to the disruptions that smartphone addicts suffer. We are skeptical of this, at least in typical cases. One reason is that these interruptions are little different from mundane urges, like hunger or needing to use the restroom. And those disruptions do not seem to undermine our rational agency, at least not in typical cases. Another reason is that urges to drink coffee or smoke do not constitute gross disruptions to our thinking processes. One can feel the urge to have a cigarette, find a place to smoke, smoke a cigarette, and get back to work all while thinking through a problem. One cannot continue to think through a problem if they are drawn in by the urge to check their social media accounts and end up reading posts, watching videos, and so on. Thus, even if cigarette and caffeine addiction threaten autonomy, they do not threaten it in the same way as wireless mobile devices.

${ }^{21}$ Henry H. Wilmer, Lauren E. Sherman, and Jason M. Chein, 'Smartphones and Cognition: A Review of Research Exploring the Links between Mobile Technology Habits and Cognitive Functioning.' Frontiers in Psychology 8 (2017). 
This is compounded by the fact that internet-connected screens are almost entirely unavoidable in contemporary life, especially in certain lines of work and in almost all areas of study. Many of us cannot do our work without being confronted with the temptation to check the websites, apps, and messages that drive smartphone addiction. Put another way, our work and study environments are - at present-structured so as to make actual and potential smartphone addicts extremely and constantly vulnerable to the hijacking of their attention and the deepening of the addiction, via runs through Hook Cycles.

Authors like Cal Newport, who coined the term "digital minimalism," argue that we would be better off if we restructured our relationships with technology on our own terms. He understands digital minimalism as, "A philosophy of technology use in which you focus your online time on a small number of carefully selected and optimized activities that strongly support things you value, and then happily miss out on everything else." ${ }^{22}$ A philosophy of technology use is a personal philosophy that "covers [...] which digital tools we allow into our life, for what reasons, and under what constraints." 23

Newport's definition outlines a noble ideal, but we are happy to adopt a less demanding understanding of the notion. For one, we do not think that users must ensure that time spent online is restricted to a small number of optimal activities. We are happy to settle for a reasonable number (or amount) of activities (or time), in light of one's ends. Another difference is that we do not, in fact, think that users need to develop a philosophy of technology use. Rather, we are happy to settle for the cultivation of a disposition (which, of course, may be realized via the development of a philosophy). Thus, we understand a digital minimalist as one whose interactions with digital technology are intentional, such that they do not conflict with their ends. For most, being a minimalist will involve a serious reduction - in some cases to the point of elimination - of interaction with smartphones, smartphone apps, and social media sites. For some it may even require living up to Newport's ideal.

It is not likely that the duty to protect our autonomy compels us to abstain from using smartphones altogether. Although the problematic use of these devices threatens our rational agency, thoughtful, intentional use of them can actually enhance our capacity to pursue ends. For instance, a user who has an autonomous desire to exercise more often might download an app that uses notifications prompting her to work out. The app might remind her of a successful streak-harnessing a manipulative tactic to help her pursue an autonomously chosen end. The danger here is that the relationship with the device is often decided on terms that are not our own, even when we are pursuing an autonomous end. Someone might begin using social media in order to stay in touch with old friends. This end (and the means to pursue it) were chosen autonomously; they are products of her rational agency. Over time, however, this autonomous usage might give way to addictive behavior as she starts to check the app compulsively to see the status of her posts. She has fallen prey to a manipulative "hook cycle," and now her relationship with the technology is built on the developers' terms rather than her own.

\footnotetext{
${ }^{22}$ Newport op. cit. at p. 28.

${ }^{23}$ Newport op. cit. at p. 28.
} 
Newport may very well be right that we have prudential reasons to reduce our smartphone usage. Perhaps most people would be better off if they became digital minimalists. But if the Kantian argument that follows is sound, then we might have even more compelling reasons to adopt the end of digital minimalism: we may have moral reasons.

\section{Imperfect Duties to Oneself}

Although some ethicists reject the very notion of duties to oneself, ${ }^{24}$ Kant makes them a central component of his moral theory. He says that they "take first place, and are the most important of all." ${ }^{25}$ He goes so far as to suggest that duties to oneself are the foundation of duties to others, making them the precondition of all moral duties. ${ }^{26}$ But he worries that they have not been properly understood and claims that "no part of morals has been more defectively treated than this of the duties to oneself." ${ }^{27} \mathrm{He}$ thinks that they have been misunderstood as a mere elevation of self-interest - a duty to promote one's own happiness, which he dismisses as an absurdity. ${ }^{28}$

${ }^{24}$ Many critics have raised skeptical concerns about the possibility of duties to oneself. Kurt Baier, The Moral Point of View: A Rational Basis of Ethics (Ithaca: Cornell University Press, 1958) claims that the very notion rests on a confusion and is ultimately "absurd" (p. 218), and in the wake of the influential argument of Marcus G. Singer, 'On Duties to Oneself', Ethics, 69, 3 (1959): 202-5, duties to oneself "largely disappeared from the radar of academic philosophers" (Michael Cholbi, 'On Marcus Singer's 'On Duties to Oneself', Ethics, 125, 3 (2015): $851-53$ p. 852).

But the Kantian notion of duties to oneself has the resources to deflect these criticisms. Singer's description of rights and duties does not map onto the Kantian model of duty. On Singer's view, rights can always be waived. I may have a right to the money I lent you, but I can waive that right by forgiving the debt. I have a right to privacy, but I can waive that by posting details of my private life on social media. I have a right not to be punched in the face, but I can waive that when I enter the boxing ring. And so forth. But Kantian duties to the self (and to others) cannot be waived in this way. The humanity in my own person confers obligations upon me that cannot be waived. I am required to respect my rational agency whether I want to or not. Lara Denis, 'Kant's Ethics and Duties to Oneself', Pacific Philosophical Quarterly, 78, 4 (1997): 321-48 does an excellent job of responding to these objections and defending the Kantian concept of duties to oneself. For other defenses of duties to the self, see Schofield op. cit. and Daniel Muñoz, 'The Paradox of Duties to Oneself', Australasian Journal of Philosophy, 98, 4 (2020):691-702.

${ }^{25}$ Kant, Immanuel, Lectures on Ethics, trans. Peter Heath. Edited by Peter Heath and J.B. Schneewind (Cambridge: Cambridge University Press, 1997) [LE], 27:341.

${ }^{26}$ He makes this bold and surprising claim in the Metaphysics of Morals: "For suppose there were no such duties [to oneself]: then there would be no duties whatsoever, and so no external duties either. For I can recognize that I am under obligation to others only insofar as I at the same time put myself under obligation, since the law by virtue of which I regard myself as being under obligation proceeds in every case from my own practical reason; and in being constrained by my own reason, I am also the one constraining myself. (Immanuel Kant, Metaphysics of Morals in Practical Philosophy, trans. Mary J. Gregor (Cambridge: Cambridge University Press, 2008) [MS] 6:417-18. For an explanation and defense of this claim, see Jens Timmermann, 'Kantian Duties to the Self, Explained and Defended', Philosophy, 81, 3 (2006): 505-30; Keith Bustos, 'Defending a Kantian Conception of Duties to Self and Others', The Journal of Value Inquiry, 42, 2 (2008): 241-54; Denis op. cit.; Lara Denis, Moral Self-Regard: Duties to Oneself in Kant's Moral Theory (New York: Routledge, 2013).

${ }^{27}$ LE 27:340

${ }^{28}$ Unsurprisingly, Kant identifies Wolff as his target on this count: "It all comes of the fact that people have had no pure concept on which to base a duty to oneself. The thought has been that self-regarding duty consists in promoting one's own happiness, as Wolff also defined it; it now depends on how everyone determines his happiness, and then duty to oneself would consist of a general rule directing us to satisfy all our inclinations and promote our own happiness. This would, however, be a great hindrance thereafter to our duty to others. It is by no means the principle, though, of self-regarding duties, and the latter have nothing to do with well-being and our temporal happiness" (LE 27:341). 
Rather than grounding such duties in egoism, Kant argues that "humanity" (i.e., rational nature) has an absolute, inherent value, and this generates self-regarding obligations insofar as the agent is morally required to respect humanity in her own person. Thus, duties to oneself are derived from the humanity formulation of the categorical imperative, which tells us that we must always treat humanity, even in our own person, "as an end, never merely as a means.",29

Our aim in this section is to explain and defend this Kantian account of duties to oneself. This involves three separate tasks. First, we go into greater detail about "humanity" and what is distinctive about its value. Second, we explain how this grounds duties to oneself. And finally, we explain the distinction between perfect and imperfect duties. We are not committed to every aspect of Kant's moral theory or to the particular self-regarding duties that he defends. Our project has a more limited scope; we are simply adopting some plausible premises from Kantian moral philosophy in order to argue for the existence of duties to oneself.

\subsection{The Value of Humanity}

Kant famously claims that human beings, in virtue of their rational agency, ${ }^{30}$ have a uniquely elevated status, which he calls "dignity." This absolute worth of humanity is distinguished from other values in three notable ways: it is objective, unconditional, and non-fungible. First, an objective value is one that holds for all rational agents, and this is contrasted with relative value, which requires the presence of a contingent inclination. For instance, the value of a chocolate cake is merely relative, because it has value only insofar as agents desire it. Not everyone has this inclination (even if most of us do), ${ }^{31}$ so it cannot make a claim on the wills of all rational agents. Second, dignity is an unconditional value. Value of this kind cannot be lost, and it holds in all contexts. ${ }^{32}$ Finally, it is non-fungible, which is to say that human beings have the kind of value that does not admit of exchanges for things of equal value. Kant says in the Groundwork that "everything has either a price or a dignity. What has a price can be replaced by something else as its equivalent; what on the other hand is raised above all price and therefore admits of no equivalent has a dignity." 33

\footnotetext{
${ }^{29}$ G 4:429
}

${ }^{30}$ Kant often glosses the term "humanity" as "rational nature," but it is clear that he has agency in mind: "Rational nature is distinguished from the rest of nature by this, that it sets itself an end" Immanuel Kant, Groundwork of the Metaphysics of Morals in Practical Philosophy, trans. Mary J. Gregor. (Cambridge: Cambridge University Press, 2008) [G], 4:437.

${ }^{31}$ And whether we have the inclination or not is a contingent, empirical question. Thus, it is not the kind of thing that can be necessary or universal.

${ }^{32}$ This is why Kant makes dignity dependent on "humanity" rather than on the possession of some kind of moral feature (such as the good will). If the dignity of human beings was dependent on moral behavior, then it would not be unconditional. For a further explanation of this point, see Allen Wood, Kant's Ethical Thought (Cambridge: Cambridge University Press, 1999), p. 115-23.

${ }^{33} G 4: 434$. Kant seems to have thought that this claim about the inherent value of human beings did not need further argument. He may have taken it to be self-evident. Indeed, this is what Allen Wood says about it: "Kant presents it as he does, however, by way of acknowledging that as a claim about ultimate value, the proposition that humanity is an end in itself is indemonstrable. The only way to convince us that rational nature has such value, therefore, is to show that we already do (and that we must) value it in this way. Kant's procedure could therefore be aptly compared with Mill's idea that principles of ultimate value cannot be demonstrated but can be argued for 


\subsection{The Duty of Respect}

In order to move from the absolute value of humanity to the existence of particular duties, however, additional steps must be taken. This can be done in a variety of ways. But one approach draws on Kant's assertion that "respect" is the only appropriate attitude to adopt with regard to the dignity of rational nature. ${ }^{34}$ This claim allows us to make an argument that bridges the gap between the value of rational nature and the humanity formulation of the categorical imperative. On this view, our actions can either express or fail to express the kind of respect that is becoming of human dignity. ${ }^{35}$ For instance, when I make a false promise to the banker about repaying a loan, my action expresses disrespect for the banker. If I recognize that rational agency (the capacity to set ends) is a faculty that deserves respect, then I cannot, on pain of inconsistency, disrespect the ends of other agents as if they did not matter.

It is this demand for respect that gives rise to the formula of humanity. ${ }^{36}$ Kant says that you must "act that you use humanity, whether in your own person or in the person of any other, always at the same time as an end, never merely as a means." ${ }^{37}$ Naturally, this leads to self-regarding duties. Given that humanity (i.e., rational nature) has dignity, we must respect it even in our own person. We therefore have duties to ourselves. Kant argues, for instance, that it would be wrong to commit suicide in order to avoid a life that promises more pain than pleasure. ${ }^{38}$ This is because suicide throws away one's rational nature and thus fails to express proper respect for it. If we were to put this in consequentialist language, we could say that rational agency has a value that is lexically prior to that of pleasure. So discarding one's rational nature in order forestall emotional pain is a bad tradeoff. 39

\subsection{Perfect and Imperfect Duties}

rationally (and even 'proven' in a looser sense of 'proof'), by showing that what the principle takes to be valuable is already 'in theory and in practice, acknowledged to be an end"' (Wood op. cit. at p. 125).

But that is not to say that he leaves us with no resources to marshal such an argument on his behalf. Christine Korsgaard, The Sources of Normativity (Cambridge; New York: Cambridge University Press, 1996b) provides a particularly plausible defense of the claim. In brief, her argument says that if we value anything then we must first value rational agency because it is the source of all value. As the source of value for all ends, rational nature must be an end in itself." Although we cannot defend this argument here, we believe that such an argument can successfully establish the inherent value of rational agency.

${ }^{34} G$ 4:436

${ }^{35}$ Wood op. cit. does an excellent job of formulating this argument and providing textual evidence for it (141-50). Samuel J. Kerstein, How to Treat Persons (Oxford: Oxford University Press, 2013) calls this the Respect-Expression Approach.

${ }^{36}$ Once again, Wood op. cit. puts this point very nicely: "What FH fundamentally demands of our actions is instead that they express proper respect or reverence for the worth of humanity [...] Though FH takes the form of a rule or commandment, what it basically asserts is the existence of a substantive value to be respected. This value does not take the form of a desired object to be brought about, but rather the value of something existing, which is to be respected, esteemed, or honored in our actions" (Wood op. cit. at p. 141).

${ }^{37} G$ 4:429

${ }^{38} G 4: 422$

${ }^{39}$ For a Kantian discussion of suicide, see J. David Velleman, 'A Right of Self-Termination?', Ethics, 109, 3 (1999): 606-28. For an interesting discussion of 'Kantian Consequentialism', see David Cumminsky, 'Kantian Consequentialism', Ethics, 31 (1990). 
The formula of humanity not only provides a perspicuous way of understanding duties to oneself, it directly grounds those duties. It is in virtue of this obligation that we have such duties to ourselves. Kant himself uses the formula of humanity to derive most of the duties to oneself that he discusses in the Metaphysics of Morals. ${ }^{40}$ There (and elsewhere) he makes an important distinction between perfect and imperfect duties. First, perfect duties refer to actions that are strictly forbidden, admitting no exceptions. This is how Kant thinks of promise-breaking and suicide. There is no latitude when it comes to such prohibitions. ${ }^{41}$ These can typically be derived from the "never as a mere means" clause. Making a false promise to the banker treats her as a mere means and disrespects her rational nature. Imperfect duties, on the other hand, stem from the obligation to respect humanity "always as an end." Kant claims that this obligates us to adopt certain ends (e.g., the happiness of others, our natural and moral perfection, etc.). Imperfect duties are obligations to pursue ends, but they do not tell us how much to pursue those ends and they do not endorse particular actions through which those ends must be pursued. ${ }^{42}$ For instance, Kant thinks we have a duty to cultivate our natural abilities; this is an end that we are obligated to adopt. But, how and to what extent we pursue this obligatory end is a matter of discretion. ${ }^{43}$

With these pieces of Kantian ethics in place, we can now put forward the argument that will be needed to ground a crucial premise in our argument for the imperfect duty to be a digital minimalist:

P1. Humanity (i.e. rational agency) has an objective, unconditional, non-fungible value - dignity.

P2. Anything that has dignity ought to be respected as an end and never treated as a mere means.

P3. If humanity ought to be respected as an end and never treated as a mere means, then we have an imperfect duty to cultivate and protect our rational agency.

Therefore,

${ }^{40}$ See MS 6:417ff. Lara Denis writes, "Kant himself employs FH more than any other principle in his explication of, and justifications for, particular duties to oneself and classes of duties to oneself. For instance, Kant's exposition of self-regarding duties in the Metaphysics of Morals primarily employs concepts related to FH: concepts such as humanity, ends, means, personality, dignity, and self-respect" 2013,324).

${ }^{41}$ Thomas Hill, 'Kant on Imperfect Duty and Supererogation', Kant Studien, 62, (1971): 55-76 says that a perfect duty has this form: "One must never (or always) $\Phi$ to the fullest extent possible."

${ }^{42}$ For more on the distinction between perfect and imperfect duties, see Wood op. cit. p. 44; Denis op. cit., p. 326; Christine M. Korsgaard, Creating the Kingdom of Ends (Cambridge; New York: Cambridge University Press, 1996), p. 84.

${ }^{43}$ The case is similar with duties to others, such as the duty of beneficence. Kant thinks that we ought to make the happiness of others one of our ends. But this does not mean that we are required to pursue the happiness of all others at all times. The Kantian duty of beneficence is thus significantly less demanding than the maximizing constraint of classical utilitarianism. We must promote the happiness of others, but there is wide latitude in how we pursue this end. 
C1. We have an imperfect duty to cultivate and protect our rational agency.

This conclusion follows naturally enough from Kantian ethical principles. But an additional premise is needed in order to justify the conclusion that we ought to be digital minimalists.

\section{The Imperfect Duty to be a Digital Minimalist}

In section 2, we argued that addiction to (or the compulsive use of) wireless mobile devices constitutes a kind of technological heteronomy. In many cases, it is incompatible with our capacity to govern ourselves. And in section 3, we argued that we have a duty to cultivate and protect our rational agency. This brings us to our central argument:

C1. We have an imperfect duty to cultivate and protect our rational agency.

P4. If we have an imperfect duty to cultivate and protect our rational agency, then we ought to adopt the end of digital minimalism.

Therefore,

C2. We ought to adopt the end of digital minimalism.

It should come as no surprise that Kantian ethics involves a duty to foster and safeguard one's own rational agency. ${ }^{44}$ But the connection of this duty to digital minimalism might be less obvious. Although section 2 outlined the effect that wireless mobile devices can have on our personal autonomy, more should be said in defense of P4.

In his prominent defense of the duty of self-respect, Thomas Hill argues that servility is objectionable because the servile person has a "tendency to disavow his own moral rights either because he misunderstands them or because he cares little for them." ${ }^{45}$ On Kant's account, servility is contrary to our duty of self-respect. The moral law requires us to recognize the moral status of all rational agents, and the servile person fails to respect humanity in her own person.

Carol Hay makes a similar (but importantly distinct) argument, as she claims that oppressed people have a duty to resist their own oppression. ${ }^{46}$ Hay points out that, when it comes to the acquiescence in one's own oppression, if you restrict your focus to the failure to respect the value of rational nature, "then you might overlook some of the concrete ways one's rational nature can actually be harmed by this acquiescence." ${ }^{47}$ She argues that oppression can harm

${ }^{44}$ We derived this conclusion from Kant's own claims about the dignity of rational agency, but it could also be defended by means of a Kant-inspired argument such as that of Korsgaard op. cit. (1996): if we value anything, we must respect our rational agency as an end in itself because it is the source of that value.

${ }^{45}$ Thomas Hill, 'Servility and Self-Respect', The Monist, 57, 1, (1973): 87-104, p. 97.

${ }^{46}$ Carol Hay, 'The Obligation to Resist Oppression', Journal of Social Philosophy, 42, 1 (2011): 21-45.

${ }^{47}$ Hay, op. cit. at p. 23. 
one's rational agency in a number of ways: it can lead to self-deception, akrasia, and a diminished capacity for rational deliberation. If we share Kant's commitments about the ultimate value of rational nature, then we have a moral duty to protect our rational capacities. Thus she concludes that oppressed people have an obligation to resist their own oppression.

An analogous argument can be made regarding our relationship with wireless mobile devices. It is not merely that the compulsive use of one's phone is inconsistent with one's higher-order desires or long-term plans (although that is often the case, as it was with Povistky's desire to read books). What is even more pernicious is the effect that these devices can have on our rational capacities. Not only is Povistky's first-order desire to look at Instagram inconsistent with her higher-order desires, the use of her phone over time actually makes her less capable of satisfying those desires.

Wireless mobile devices can weaken our rational agency. They distract us, shorten our attention spans, and make it harder for us to stick to a difficult task. Insofar as we value rational agency, we ought to recognize the threat that these devices pose to it. We should be intentional about how we use them in order to safeguard our capacity to set ends for ourselves and pursue those ends. And that is precisely what it means to be a digital minimalist.

Although this conclusion was derived from Kantian premises, it is likely that other normative theories will lead to the same conclusion. Consequentialists who consider autonomy in their theory of the good (either because it is intrinsically or instrumentally good) are also likely to endorse digital minimalism. Even consequentialists who do not explicitly concern themselves with autonomy can agree that it would be good to mitigate the aforementioned harms associated with the problematic use of wireless mobile devices and other addictive technologies. An ethical egoist would agree that an addiction that undermines one's ability to pursue other ends is not in her best self-interest. Finally, virtue ethics and perfectionist moral theories are also likely to endorse digital minimalism on the grounds that addictions of this kind detract from human flourishing. It would, of course, be impossible to give an exhaustive list, but perhaps these suffice to show that although we have presented a Kantian argument in this paper, there are surely moral reasons derived from other normative theories that weigh in favor of digital minimalism.

\section{Conclusion}

We have argued that there is a moral obligation to be intentional about our use of smartphones and other addictive devices. We have this duty because we are required to protect the most valuable commodity we possess - autonomy. Kant believes that the proper exercise of our autonomy is the only thing that is good without qualification-something that shines "like a jewel" having its "full worth in itself." 48 To wantonly forfeit some of our agency by falling prey to technological heteronomy is to demonstrate a failure to respect this precious capacity as the treasure that it is.

${ }^{48} G 4: 394$ 


\section{Acknowledgments}

We are grateful to FIU's chapter of Phi Sigma Tau and two anonymous reviewers for helpful feedback that greatly improved the quality of this paper. 